\title{
Odor learning improves efficacy of egg parasitoids as biocontrol agents against Tuta absoluta
}

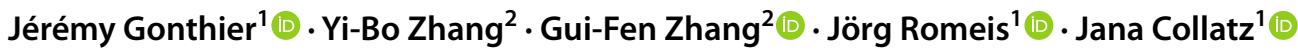

Received: 9 June 2021 / Revised: 13 December 2021 / Accepted: 31 January 2022 / Published online: 28 February 2022

(c) The Author(s) 2022

\begin{abstract}
Trichogramma spp. (Hymenoptera: Trichogrammatidae) are generalist egg parasitoids widely used as biological control agents, yet with limited efficacy against Tuta absoluta (Meyrick; Lepidoptera: Gelechiidae), a key pest of tomato. Olfactory cues related to the host-plant complex influence the searching behavior in parasitoids. Studies have shown that female Trichogramma spp. can learn odor cues affecting their preference. We assessed if learning increases the response to tomato odor and whether it improves the parasitism rate of Trichogramma achaeae, Trichogramma evanescens, and Trichogramma dendrolimi. The parasitoids were either naive, reared for one generation on T. absoluta eggs, or conditioned associatively with an oviposition experience on a factitious host in the presence of tomato odor. Subsequently, their arrestment response (searching time) to T. absoluta-infested tomato leaves was observed in a static four-chamber olfactometer. Rearing the parasitoids on $T$. absoluta increased the arrestment time of $T$. dendrolimi strongly and that of $T$. evanescens slightly but not that of $T$. achaeae. In contrast, oviposition experience on a factitious host with the tomato odor (leaves or extract) increased the searching time of $T$. achaeae and $T$. evanescens strongly but did not improve the response of $T$. dendrolimi. Concerning parasitism improvement, only $T$. achaeae showed an increased parasitism rate after associative learning. Hence, the learning capacity of $T$. achaeae should be further explored to improve its biological control efficacy against T. absoluta.
\end{abstract}

Keywords Tomato pinworm · Biological control · Odor conditioning · Olfactometer · Trichogramma efficiency

\section{Key messages}

- We investigated the response of Trichogramma parasitoids to tomato leaves in an olfactometer.

- The odor of tomato leaves innately repelled all three species.

- Learning enhanced the arrestment response of all three species in the olfactometer.

- The conditioning process suitable to induce learning differed among species.

Communicated by Su Wang.

Jana Collatz

jana.collatz@agroscope.admin.ch

1 Agroscope, Research Division Agroecology and Environment, Reckenholzstrasse 191, 8046 Zurich, Switzerland

2 Plant Protection Institute, Chinese Academy of Agricultural Sciences, Beijing, China
- Only for T. achaeae, learning translated into a higher parasitism efficacy.

\section{Introduction}

Hymenopteran parasitoids are contributing to the reduction of important arthropod pest species worldwide. Parasitoid wasps lay their eggs in or on the body of other arthropods, where the immatures will develop, resulting in the host's death. The efficiency of host searching behavior is determinant for the reproductive success of the female parasitoid wasps. For parasitoids of herbivorous hosts, their searching ability often relies on their response to odor cues from the host and the host plant (Bjorksten and Hoffmann 1998; Takasu and Lewis 2003; Vet and Groenewold 1990). This response may be affected by genetic mechanisms (Prevost and Lewis 1990; Gu and Dorn 2000) or learning (Kruidhof et al. 2019). Learning can occur through different processes and at diverse moments during the life cycle of a parasitoid. When emerging, for instance, a wasp can learn the cues of its 
environment (Kester and Barbosa 1991; Hastings and Godfray 1999). Adult wasps can establish an association between two stimuli or between a stimulus and a response through experience, the so-called associative learning (Kruidhof et al. 2019). Learning behavior can be exploited for manipulating the efficacy of augmentative biological pest control as parasitoids can be conditioned to become more efficient in the different phases involved in host searching and host acceptance (Giunti et al. 2015; Kruidhof et al. 2019).

Generalist egg parasitoids of the genus Trichogramma (Hymenoptera: Trichogrammatidae) are common natural enemies of many Lepidoptera species. They are relatively easy to mass-rear and are successfully used in inundative and inoculative biological control programs worldwide (van Lenteren 2000). It has been shown that Trichogramma spp. can learn volatile plant compounds (Bjorksten and Hoffmann 1995; Pashalidou et al. 2010; Wilson and Woods 2016). Recent attempts have been made to use Trichogramma spp. against Tuta absoluta (Meyrick) (Lepidoptera: Gelechiidae) in Europe (Urbaneja et al. 2012; Zappalà et al. 2013). This key pest of tomato has become a significant threat to tomato production in Europe and Africa (Biondi et al. 2018; Mansour et al. 2018) and has reached China in 2017, the worldwide biggest tomato producer (Zhang et al. 2020a). Populations of T. absoluta established first in the province Xinjiang (Zhang et al. 2020a), followed by Yunnan (Zhang et al. 2020b), Guizhou, Sichuan, Hunan, Guangxi, and Chongqing, causing severe damage in Xinjiang (yield losses up to 86\%) and Yunnan (Zhang et al. 2021). To control the pest, Chinese tomato growers currently rely on insecticides, including Emamectin benzoate, Avermectin-chlorobenzoyl, Methoxy fenozide, and Chlorantraniliprole (Amire et al. 2020), as well as on the microbial pesticide Bacillus thuringiensis (Bt-G033A) (Zhang et al. 2020c). However, T. absoluta has developed high levels of resistance to several of the most popular insecticides, thus implying that the invading individuals may already bear or will develop resistance to those insecticides (Han et al. 2018; Guedes et al. 2019; Desneux et al. 2021). Therefore, new tools that are safe for human health and the environment are highly needed for managing this invasive pest. The egg parasitoids Trichogramma spp. are one possible option. Unfortunately, in Europe, several factors limit the success of Trichogramma spp. in augmentative biological control against $T$. absoluta, such as the low attraction to infested tomato plants (Milonas et al. 2019) and the fact that $T$. absoluta eggs are not laid as egg patches (Tropea et al. 2012). Our study aimed to evaluate if learning can improve the success of Trichogramma spp. against T. absoluta.

We focused on three commercially available species, namely Trichogramma achaeae Nagaraja \& Nagarkatti, Trichogramma evanescens Westwood, and Trichogramma dendrolimi Matsumura. We selected T. achaeae since this species is currently used for biological control of T. absoluta in Europe (Desneux et al. 2021) and T. evanescens and T. dendrolimi, as both are commonly occurring in China (Zang et al. 2021). In China, T. dendrolimi is mass-reared and widely used in maize fields against the Asian corn borer (ACB) Ostrinia furnacalis Guenée (Lepidoptera: Crambidae) and to a lesser extent on rice fields against Chilo suppressalis Walker (Lepidoptera: Crambidae) (Zang et al. 2021).

The aims were to explore different mechanisms by which experience increases parasitoid attraction toward tomato plants and whether this differs between Trichogramma species. To address this, three questions were investigated: (1) What is the innate response of the parasitoids to volatile cues of the tomato plant? (2) Does experience of cues from host remains and tomato plants at emergence improve this response? (3) Does an oviposition experience in the presence of tomato plant cues result in associative learning and increased preference to the plant-host complex? Finally, we explored whether the behavior modified by learning in the three Trichogramma species translates into differences in parasitism efficacy.

\section{Materials and methods}

\section{Plants and insects}

Tomato plants, Solanum lycopersicon cv. Rentita, were grown in greenhouses at $25 \pm 5^{\circ} \mathrm{C}$ and $60 \pm 10 \% \mathrm{RH}$. Plants were grown in pots (10 $\mathrm{cm}$ dia.) with long-term fertilizer mixed with the soil $\left(3 \mathrm{~kg} / \mathrm{m}^{3}\right.$, Manna Cote $4 \mathrm{M}$, Hauert Düngerwerke $\mathrm{GmbH}$, Germany). Eggs of T. absoluta were provided by Andermatt Biocontrol (Switzerland) and a colony was established in a climate chamber at $25 \pm 1{ }^{\circ} \mathrm{C}$, $70 \pm 10 \% \mathrm{RH}$ and a 16:8 h L:D photoperiod). Adults were kept in mesh cages $(50 \times 50 \times 50 \mathrm{~cm})($ bug dorm, MegaView Science Co., Ltd., Taiwan) and provided cotton soaked in honey-water $(10 \% \mathrm{v} / \mathrm{v})$ placed on the top of the cage and tomato plants for egg laying. After seven days, plants with eggs and young larvae were moved to a another cage to start a new colony. Moth eggs used in the experiments were between 4 and $16 \mathrm{~h}$ old.

The commercially available egg parasitoids, $T$. evanescens, T. achaeae and T. dendrolimiwere obtained from AGROLINE Bioprotect (Switzerland), Bioline AgroSciences (France), and AMW Nützlinge (Germany), respectively. Colonies of parasitoids were established on UVirradiated eggs of Ephestia kuehniella Zeller (Lepidoptera: Pyralidae) from AGROLINE Bioprotect (Switzerland) in climate chambers $\left(22 \pm 1^{\circ} \mathrm{C}, 70 \pm 10 \% \mathrm{RH}, 16: 8 \mathrm{~h} \mathrm{~L}: \mathrm{D}\right)$. Rearing was established in large acrylic glass tubes $(10 \mathrm{~cm}$ dia.; $30 \mathrm{~cm}$ length), and the parasitoids were fed on honey-agar 
Fig. 1 The Trichogramma spp. females were allowed to gain experience with tomato and host cues before the experiments. Different conditioning procedures were used. a Emergence learning (EL): parasitoids were reared for one generation on T. absoluta eggs on tomato leaflets. b Associative learning on tomato leaflet (ALT): female wasps experienced oviposition on E. kuehniella eggs placed on a tomato leaflet. c Associative learning with a tomato leaf extract (ALE): female wasps experienced oviposition on E. kuehniella eggs placed on a filter paper with tomato leaf extract. d Naive: control female wasps were reared on E. kuehniella eggs without any exposure to T. absoluta or tomato cues. This figure was created with BioRender.com

\section{Conditioning procedures}

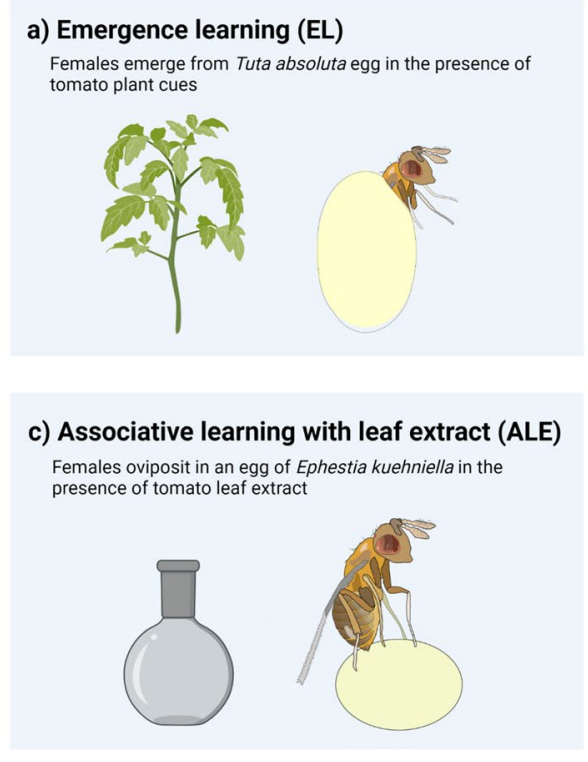

b) Associative learning on tomato leaflet (ALT) Females oviposit in an egg of Ephestia kuehniella placed on a tomato leaflet

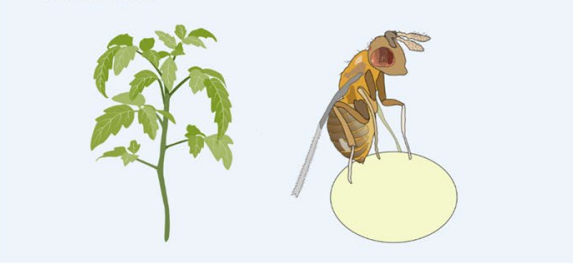

d) Naive Females have no oviposition experience nor experience of tomato plant cues

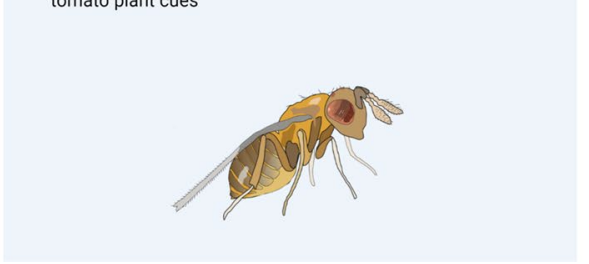

(water:agar:honey, 1 1: $8 \mathrm{~g}: 0.1$ 1). Two to three times per week, food and a post-it ${ }^{\circledR}$ with pasted fresh host eggs were added to the rearing and parasitized eggs were removed and placed in incubation containers ( $5 \mathrm{~cm}$ dia.; $10 \mathrm{~cm}$ length). After about 10 days, newly emerged adults from these containers were transferred back into the rearing tube. The parasitoid species were maintained for at least 50 generations on E. kuehniella eggs before experimentation.

For the experiments, only female wasps were used. Females and males were distinguished under a stereomicroscope by their dimorphic antennae. In females, the last flagellomeres are usually prominently enlarged, creating an apical club. In males, the antennomere number is often higher and the shape filiform (see Colazza et al. 2009). Females were between 6 and $12 \mathrm{~h}$ old and mated. In Trichogramma spp., mating takes place just after the female emerges (Waage and Ming 1984). One hour before the start of the experiment, females were isolated in small glass tubes. All experiments took place in climate chambers $\left(22 \pm 1{ }^{\circ} \mathrm{C}\right.$, $70 \pm 10 \%$ RH, 16:8 h L:D).

\section{Parasitism capacity of Trichogramma spp.}

We first characterized the parasitism capacity of the three Trichogramma species. The experiments were conducted in glass vials, where single females recieved approximately 400 eggs of E. kuehniella daily for 9 days. Parasitism, fertility and sex ratio of offspring were recorded. A detailed description of the experiments and the results can be found in the supplementary electronic material.

\section{Conditioning procedures}

The Trichogramma spp. females used in the experiments were allowed to gain experience with tomato and host cues. Different conditioning procedures were implemented (Fig. 1).

\section{Emergence learning (EL)}

Parasitoids were reared in containers covered with a fine mesh (5 cm dia.; $10 \mathrm{~cm}$ length) for one generation on $T$. absoluta eggs on tomato leaflets $(5 \pm 2 \mathrm{~cm}$ length, freshly cut from 3 weeks old plants). The eggs had been laid by $T$. absoluta onto the tomato leaves within $24 \mathrm{~h}$ before the assay. To assure the presence of cues from freshly infested tomato plants during the entire parasitoid development, the containers were placed inside cages with T. absoluta-infested tomato plants until parasitoid emergence. After emergence, the parasitoids remained in the cage for 6 to $12 \mathrm{~h}$ until used in the experiments.

\section{Associative learning on tomato leaflet (ALT)}

0.5 to $1 \mathrm{~h}$ before the experiment, female wasps experienced oviposition on E. kuehniella eggs placed on a tomato leaflet. Approximately 30 eggs of E. kuehniella were placed on a freshly cut leaflet from an uninfested tomato plant in a Petri dish (5 cm dia., $1 \mathrm{~cm}$ height). Single parasitoid females randomly selected from the rearing were placed on the leaflet and allowed to oviposit. Oviposition (i.e., egg stung with 
the ovipositor) was confirmed under the stereomicroscope. Immediately after the first oviposition, the females were individually collected with a glass aspirator and transferred into a glass vial until used in the experiments. Females that did not oviposit within $15 \mathrm{~min}$. were discarded (approximately $5 \%$ ). When testing the memory retention in a separate experiment, experienced females were kept for $24 \mathrm{~h}$ before used.

\section{Associative learning with a tomato leaf extract (ALE)}

The same procedure as described above was conducted except that, instead of a tomato leaflet, a filter paper $(5 \mathrm{~cm}$ dia.) with tomato leaf extract was used. The extract was prepared by soaking $3.5 \mathrm{~g}$ of tomato leaves for $12 \mathrm{~h}$ in $20 \mathrm{ml}$ of solvent (diethyl ether or hexane, Sigma-Aldrich Chemie Gmbh, Germany $\geq 95 \%$ purity). The solution was filtered through a cotton to remove the leaves and gently heated in a water bath at $60{ }^{\circ} \mathrm{C}$ to reduce the volume to $3.5 \mathrm{ml}$, corresponding to $1 \mathrm{~g}$ of tomato leaf per $1 \mathrm{ml}$ extract. The filter paper was placed under the fume hood, $400 \mu \mathrm{l}$ of extract were added and the solvent was allowed to evaporate for $5 \mathrm{~min}$ before the conditioning. The filter paper was exchanged between each female conditioning process.

\section{Naive}

Parasitoids were reared on E. kuehniella eggs without any exposure to T. absoluta or tomato cues. They served as control in the experiments.

\section{Olfactometer assays}

\section{Experimental setup}

To test the arrestment response of the Trichogramma spp. females to the cues of infested tomato leaves, we used a static four-chamber olfactometer (10 cm dia.), which consisted of a bottom with four chambers, which were covered with a fine mesh providing a walking arena (height $0.5 \mathrm{~cm}$ ), and a lid made of a glass plate (Collatz et al. 2006). The walking arena was divided in four sectors corresponding to the four olfactometer chambers. The mesh prevented access of the parasitoids to the chambers. The experiments took place in a climate chamber at $22{ }^{\circ} \mathrm{C}$ and $70 \% \mathrm{RH}$. A freshly cut tomato leaflet infested with approximately $30 \mathrm{~T}$. absoluta eggs ( $<24 \mathrm{~h}$ old) was placed in one sector of the olfactometer. Factitious leaflets made of green paper of the same size were placed in each of the other sectors. The olfactometer was placed in a cardboard box illuminated from the top to avoid any directional light attraction. One Trichogramma spp. female at a time was placed on the walking arena and allowed to settle for $5 \mathrm{~s}$. Subsequently, the time spent on each of the four chambers was recorded for 5 min using the Software the Observer XT11 (Noldus, Netherlands). The positions of the factitious and tomato leaflets were swapped between each replicate to minimize location bias. Every hour, new tomato and factitious leaflets were used. After each series of observation, the chambers were cleaned with 98\% Ethanol to remove any remaining volatiles.

\section{Experimental design}

In the first experiment, we tested the arrestment response of female T. achaeae after the following conditioning procedures: (a) EL; (b) ALT; (c) ALT after $24 \mathrm{~h}$. We evaluated in parallel if ALT females discriminate between infested and uninfested leaves. We arranged a choice test by placing an infested tomato leaflet into the test chamber and an uninfested leaflet in the control chamber of the olfactometer. In the second experiment, we tested the response of female T. achaeae after the following conditioning procedures: (a) ALE with diethyl ether; (b) ALE with hexane. Finally, in the last experiment, we tested the response of female T. evanescens and T. dendrolimi after the following conditioning procedures: (a) EL (b) ALT. For each assay, naive wasps were tested as control.

Just after being used in the experiment, all naive and EL females were offered E. kuehniella eggs for a maximum of $15 \mathrm{~min}$. Females that did not oviposit were discarded (approximately 5\% across groups). This was done to minimize the bias in the associative learning treatments by selecting only females motivated to oviposit during the first 15 min conditioning period before the experiment-the final sample sizes range from 16 to 28 individuals across groups.

\section{Efficacy assays in tubes}

\section{Experimental setup}

Experiments were conducted with all three Trichogramma species to test whether the conditioning leading to an increased arrestment response in the olfactometer also increases parasitism efficacy compared to naive females. Mated parasitoid females of the conditioning treatments that resulted in arrestment response in the olfactometer were placed individually in glass tubes $(3 \mathrm{~cm}$ dia., $12 \mathrm{~cm}$ height) closed with a lid ventilated with a fine mesh and containing a single tomato leaflet with ten $T$. absoluta eggs. The eggs were collected from infested leaves and transposed at an equal distance (approximately 5-10 mm) on the abaxial side of a fresh tomato leaflet directly by hand using a fine wet pencil. The leaflet stem was placed into a solution of agar water $(8 \mathrm{~g}: 1 \mathrm{l})$ to provide moisture. 


\section{Experimental design}

Based on the results from the olfactometer experiments, we tested ALT females for T. achaeae and T. evanescens and EL females for T. dendrolimi. Trichogramma achaeae females were allowed for $2 \mathrm{~h}$ to parasitize the offered T. absoluta eggs, whereas, for T. evanescens and T. dendrolimi, the period was extended to $6 \mathrm{~h}$ since they required more time to start parasitization. In the end, the females were removed, and the tubes were incubated. After five days, the eggs parasitized (visible as blackened eggs) were counted. Between 25 and 30 replicates were conducted per parasitoid species and treatment. The experiments took place in a climate chamber at $22{ }^{\circ} \mathrm{C}, 70 \% \mathrm{RH}$, and artificial light. For each assay, naive wasps were tested as control.

\section{Efficacy assays in mesh cages}

\section{Experimental setup}

Mesh cage assays were conducted with $T$. achaeae to assess whether the conditioning leading to increased parasitism in the tube also increased the efficacy at a larger scale. Ten mated ALT females were placed together in a mesh cage ( $15 \mathrm{~cm}$ dia.; $30 \mathrm{~cm}$ height) containing a tomato compound leaf with seven leaflets. Twenty $T$. absoluta eggs were transposed on each leaflet ( 2 to 3 eggs per leaflet at an equal distance) on the abaxial side directly by hand using a fine wet pencil. The leaf stem was placed into a solution of agar water to provide moisture.

\section{Experimental design}

T. achaeae females were allowed four days to parasitize the eggs. The eggs parasitized were counted four days later. Twenty replicates each were conducted for ALT females and naive females as control. The experiments took place in a climate chamber at $22{ }^{\circ} \mathrm{C}, 70 \% \mathrm{RH}$ and 16:8 $\mathrm{h} \mathrm{L}: \mathrm{D}$.

\section{Statistical analysis}

For statistical analysis, the computer software NCSS (2020) (NCSS, LLC, US) was used. Data were tested for normal distribution using the Shapiro-Wilk test, and visual inspections of the data were made using Q-Q-plots. Since data were not normally distributed, we used a Wilcoxon signedrank test to analyze the arrestment response of parasitoids to infested tomato leaves, i.e., to compare the time spent above the chamber with the infested leaflet to the time spent above the opposite chamber of the four-chamber olfactometer. For the efficacy tests, data were normally distributed, and variance was homogenous (Modified-Levene equal variance test). We considered the females laying zero eggs during the time allowed as not responding. A chi-square test of independence was performed to examine the relation between the treatment and the number of females not responding during the time allowed. For females that had oviposited, a twosample unpaired $t$ test of equal variance was used to compare the mean number of eggs parasitized between the treatments. For all analyses, we considered a $p$ value lower than 0.05 as statistically significant.

\section{Result}

\section{Olfactometer assays}

In all three Trichogramma species, naive females spent more time on the control chamber than the chamber containing the infested tomato leaflet (Figs. 2, 3, 4). However, this deterrence from the tomato leaflet was only significant in two trials with female $T$. achaeae (Wilcoxon signed-rank test; $z=2.05, p=0.039$, Fig. 2b; $z=2.46, p=0.013$, Fig. 3a).

\section{Trichogramma achaeae}

EL females spent more time on the control chamber than on the test chamber containing the infested tomato leaflet (Fig. 2a). This difference, however, was not significant. In contrast, ALT females spent significantly more time on the test chamber than on the control chamber $(z=3.12$, $p=0.002$; Fig. 2b). When given a choice between an infested and an uninfested tomato leaflet, ALT females did not show any difference in searching time $(z=0.37, p=0.708$; Fig. 2b). When tested $24 \mathrm{~h}$ after the learning experience, ALT females spent numerically but not significantly more time on the test chamber than on the control chamber $(z=1.34, p=0.178$; Fig. $2 \mathrm{c})$. When tomato leaves were extracted with diethyl ether, ALE females spent significantly more time on the test chamber containing the plant extract than on the control chamber $(z=2.21, p=0.002$; Fig. 3a). However, the females did not respond to the test chamber when tomato leaves were extracted with hexane (Fig. 3b).

\section{Trichogramma evanescens and T. dendrolimi}

ALT female T. evanescens spent significantly more time on the chamber containing an infested tomato leaflet than on the control chamber $(z=2.68, p=0.007$; Fig. $4 \mathrm{a})$, while EL female $T$. evanescens spent similar time on the test and control chambers (Fig. 4a). On the opposite, ALT female T. dendrolimi spent similar time on the test and control chambers 


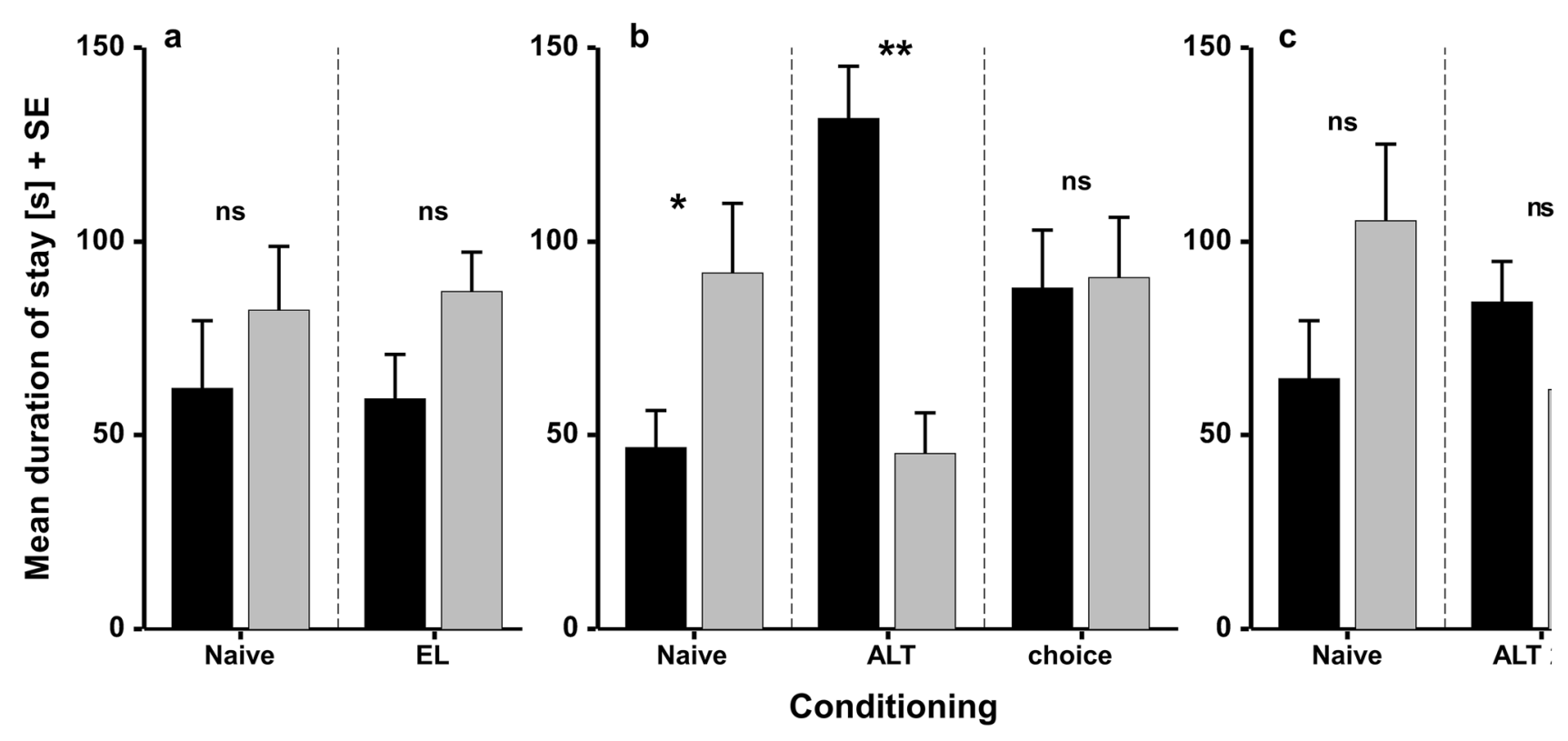

Fig. 2 Walking time (mean $+\mathrm{SE}$ ) of female Trichogramma achaeae in the odor chambers of a four-chamber olfactometer during $5 \mathrm{~min}$. after different conditioning. One chamber contained a tomato leaflet infested with Tuta absoluta eggs, and the opposite control chamber a factitious leaflet made from green paper. a Naive $=$ control $(n=18)$; EL $=$ Emergence learning, $\quad(n=20) . \quad$ b Naive $=$ control $\quad(n=20)$; ALT $=$ Associative learning on tomato leaflet $(n=28)$; ALT choice
$=$ Associative learning on tomato leaflet $(n=20)$. Instead of a factitious paper leaflet, an uninfested tomato leaflet was placed in the control chamber of the olfactometer. $\mathbf{c}$ Naive $=\operatorname{control}(n=20)$; ALT $24 \mathrm{~h}$ $=$ Associative learning on tomato leaflet happened $24 \mathrm{~h}$ before the experiment $(n=20)$. ns. not significant; $* P<0.05$; $* * P<0.01$ (Wilcoxon signed-rank test)

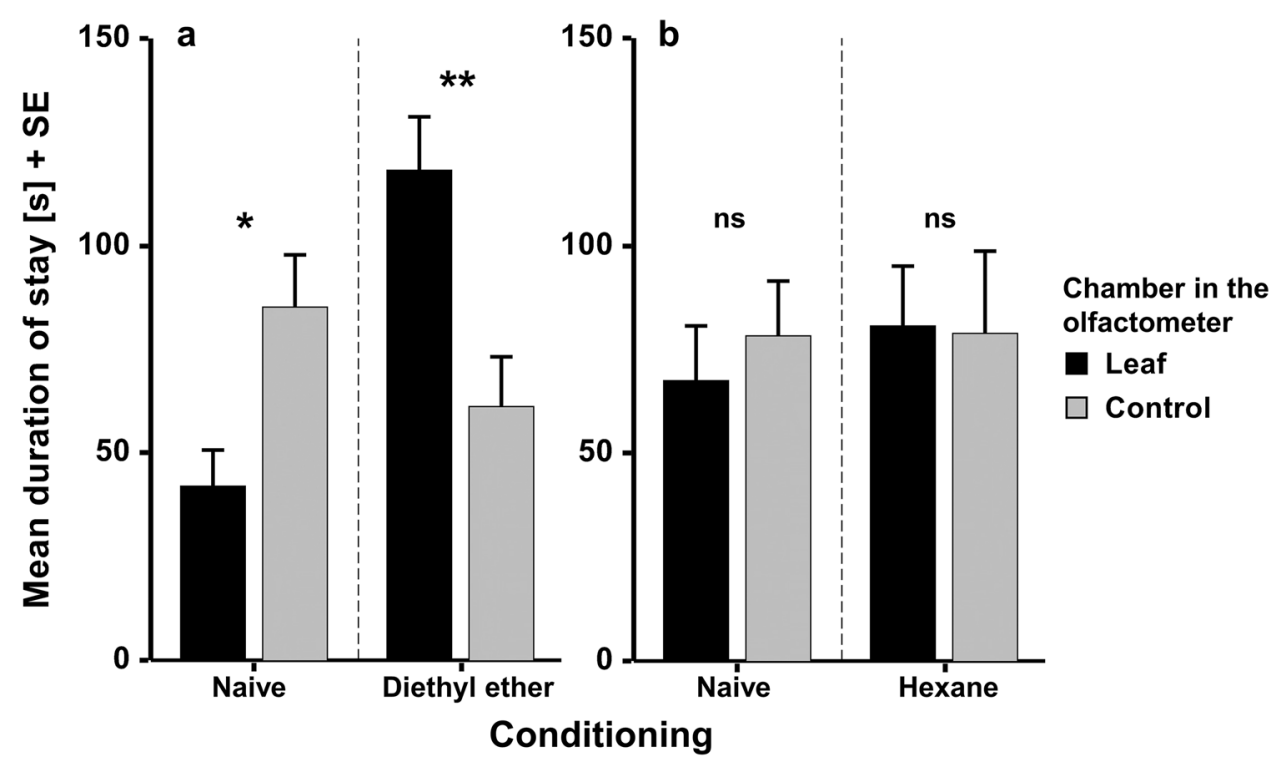

Fig. 3 Walking time (mean $+\mathrm{SE}$ ) of female Trichogramma achaeae in the odor chambers of a four-chamber olfactometer during $5 \mathrm{~min}$. after different conditioning. One chamber contained a tomato leaflet infested with Tuta absoluta eggs, and the opposite control chamber a factitious leaflet made from green paper. a Naive $=$ control $(n=20)$;
Diethyl ether $=$ Associative learning on tomato extract (ALE females) using diethyl ether as solvent $(n=20)$. b Naive $=$ control $(n=22)$; Hexane $=$ Associative learning on tomato extract (ALE females) using hexane as solvent $(n=15)$. ns. not significant; $* P<0.05 ; * * P<0.01$ (Wilcoxon signed-rank test) 


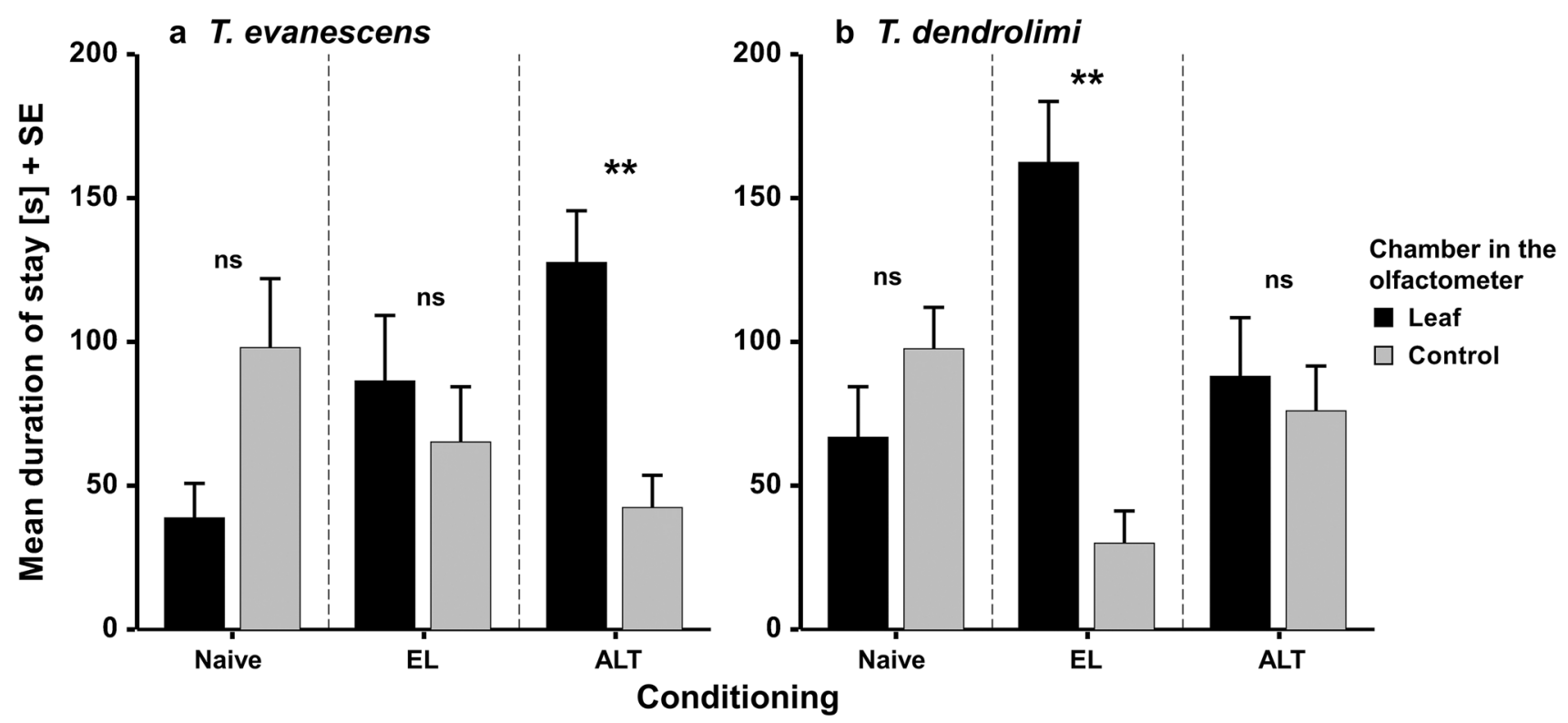

Fig. 4 Walking time (mean + SE) of female Trichogramma evanescens and dendrolimi in the odor chambers of a four-chamber olfactometer during $5 \mathrm{~min}$. after different conditioning. One chamber contained a tomato leaflet infested with Tuta absoluta eggs, and the opposite control chamber a factitious leaflet made from green

(Fig. 4b), while EL female T. dendrolimi spent significantly more time on the test chamber than on the control chamber $(z=3.09, p=0.002$; Fig. 4b).

\section{Efficacy test}

\section{Tube assays}

When Trichogramma spp. females were allowed to parasitize T. absoluta eggs on a tomato leaflet, ALT female T. achaeae were more likely than naive females to parasitize at least one egg $\left(X^{2}=9.36, d f=1, N=52, p=0.002\right)$; of ALT females, $88 \%$ parasitized one or more eggs whereas only $48 \%$ of the naive females did. In addition, ALT females parasitized significantly more eggs than the naive ones (unpaired $t$ test of equal variance, $t=2.24, N=33, p=0.03$; Fig. 5a). In contrast, ALT female $T$. evanescens did not parasitize more eggs than the naive females $(t=-0.19, N=34, p=0.842$; Fig. 5b); $48 \%$ ALT females and $56 \%$ naive females parasitized one or more eggs $\left(X^{2}=0.138, d f=1, N=61\right.$, $p=0.709$ ). Also, no difference was observed in the number of eggs parasitized by the naive and EL female $T$. dendrolimi $(t=0.57, N=40, p=0.567$; Fig. 5 c) ; 66\% EL females and $73 \%$ naive females parasited one or more egg $\left(X^{2}=0.317\right.$, $d f=1, N=60, p=0.573)$. paper. a Naive $=$ control $(n=20) ; \mathrm{EL}=$ Emergence learning $(n=16)$; ALT $=$ Associative learning on tomato leaflet $(n=20)$. $\mathbf{b}$ Naive $=$ control $(n=20)$; EL $=$ Emergence learning $(n=16) ;$ ALT $=$ Associative learning on tomato leaflet $(n=20)$. ns. not significant; $* * P<0.01$ (Wilcoxon signed-rank test)

\section{Mesh cage assay}

When T. achaeae were allowed to parasitize T. absoluta eggs on a compound tomato leaf, ALT females parasitized significantly more eggs than the naive ones $(t=2.9, N=31$, $p=0.007$; Fig. 5d). Overall, $80 \%$ of females in both treatments (ALT and naive) parasitized at least one egg.

\section{Discussion}

Our study provides clear evidence for three species of Trichogramma that they can learn odor cues from the host-plant complex of tomato plants infested with $T$. absoluta eggs. While in T. achaeae and T. evanescens, associative learning resulted in an increased arrestment response in a fourchamber olfactometer, the primary learning mechanism in T. dendrolimi was emergence learning. Furthermore, in T. achaeae, but not in the other two species, the increase in arrestment response translated into a higher parasitism efficiency of T. absoluta eggs on tomato in small-scale laboratory assays.

The odor of tomato leaves infested with $T$. absoluta eggs innately repelled naive females of all three Trichogramma species. This is likely one reason explaining the low suitability of the tomato crop for supporting Trichogramma spp. parasitoids (Giorgini et al. 2019). That naive parasitoids are repelled by particular plant odors has been 

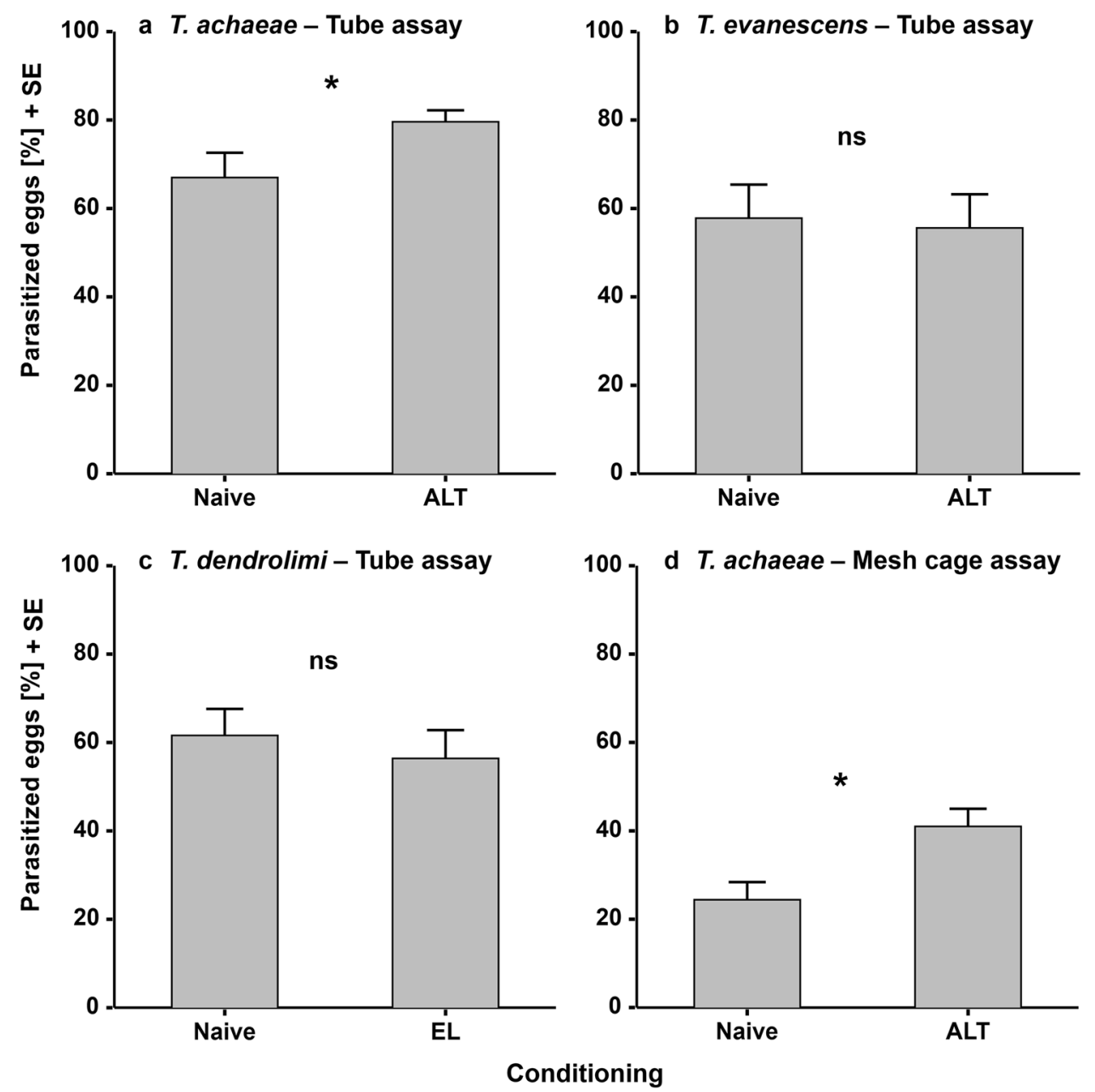

Fig. 5 Parasitism of Tuta absoluta eggs under laboratory conditions. Mean percentage (+SE) of parasitized T. absoluta eggs per Trichogramma species and conditioning. The tube assay consisted of a single tomato leaflet (with 10 eggs) and a single female per replicate; the mesh cage assay of a compound tomato leaf (seven leaflets with 20 eggs) and 10 females per replicate. a Number of eggs parasitized after $2 \mathrm{~h}$ by Trichogramma achaeae in tube assay; Naive $=$ control $(n=27)$; ALT $=$ associative learning on tomato leaflet $(n=25)$. b

reported before. For example, Romeis et al. (1997) showed that female Trichogramma chilonis Ishii were repelled by volatiles from pigeon pea (Cajanus cajan) plants in the reproductive stage. It has been hypothesized that repelling odors will likely be found in systems where the interactants have not coevolved closely (Romeis et al. 1997). In our study, the three strains tested likely have no common origin with T. absoluta, which is native to South America (CABI 2021, Invasive Species Compendium). Corroborating this hypothesis, Trichogramma pretiosum Riley, from the area of origin of T. absoluta, have been reported to innately respond to volatiles from tomato (Nordlund et al. 1985). Therefore, repellent volatiles might be a limiting factor for using new associations in biological control.
Number of eggs parasitized after $6 \mathrm{~h}$ by Trichogramma evanescens in tube assay; Naive $=$ control $(n=31)$; ALT $=$ associative learning on tomato leaflet $(n=30)$. $\mathbf{c}$ Number of eggs parasitized after $6 \mathrm{~h}$ by Trichogramma dendrolimi in tube assay; Naive $=$ control $(n=30)$; $\mathrm{EL}=$ Emergence learning $(n=30)$. $\mathbf{d}$ Number of eggs parasitized after 4 days by $T$. achaeae in mesh cage assay; Naive = control $(n=16)$; ALT $=$ associative learning on tomato leaflet $(n=16)$. ns. not significant; $* P<0.05$ (two-sample unpaired $t$ test of equal variance)

Previous studies in y-tube olfactometers with Trichogramma spp. and tomato plants infested or not by T. absoluta have reported contradictory results. Gontijo et al. (2019) found that naive T. achaeae females were attracted to volatiles produced by tomato, regardless of their infestation status. This, however, could not be confirmed by Milonas et al. (2019). Another study has found that T. evanescens were innately attracted to cues of infested tomato plants (Alsaedi et al. 2016). Our results cannot directly be compared to those previous studies since entirely different setups were used. A repellency or arrestment response is difficult to detect in a y-tube olfactometer since non-responsive individuals are excluded. Moreover, since multiple females were tested simultaneously in the studies by Alsaedi et al. (2016) 
and Gontijo et al. (2019), an aggregation effect cannot be excluded. Another explanation for the observed differences resides in the different strains used. It is acknowledged that biological traits can differ significantly among strains of the same Trichogramma species (Hoffmann et al. 2001; ElWakeil 2007; Chailleux et al. 2012).

Our olfactometer assays showed that the learning behavior is species-specific. Female T. dendrolimi learned the cues of the host-plant complex at emergence; female T. evanescens likewise, but to a lesser extent. However, female T. achaeae did not learn the cues from the host-plant complex during development or emergence. This latter result contrasts with a study by Cascone et al. (2015), who reported that rearing $T$. achaeae on T. absoluta eggs laid on tomato plants for one generation significantly improved the attack rate against $T$. absoluta. However, in this study, the attack rate was tested in small-scale assays, and the eggs were not provided on tomato leaves.

It is generally accepted that egg parasitoids can learn odors from the host-plant complex at the time of emergence (Dukas and Duan 2000; Meiners et al. 2005; Pashalidou et al. 2010). However, few studies have compared this learning process between species. Like our result, Bjorksten and Hoffmann (1995) found that the rearing host's effects were weak or absent in the Australian egg parasitoid, Trichogramma nr. ivelae Pang \& Chen. In contrast, the host chosen initially for oviposition (associative learning) substantially impacted the later host preference. However, another study found that when reared on a tomato plant, Trichogramma brassicae Bezdenko modified their behavior, prolonging searching time compared to individuals that emerged from the same host eggs placed directly in glass vials (Bjorksten and Hoffmann 1998) demonstrating that even in the same genus, species may show very different learning mechanisms. In our study, it is possible that another rearing host than E. kuehniella may have influenced the response of $T$. dendrolimi since this species was attracted by the tomato plants after having been reared for just one generation on T. absoluta eggs. We think that this is less likely for the two other species since they did not response positively to a change of hosts.

Associative learning increased the arrestment response of female T. achaeae and T. evanescens to T. absoluta-infested tomato leaves. Since naive females showed no arrestment response and did not learn the host plant's odor at emergence, associative learning seems to be the key to improving their arrestment response to the tomato plant's odor. This finding is consistent with the results from previous studies. Trichogramma species have been reported to learn different components of host plant volatiles by associative learning and to adapt their behavior accordingly (Pashalidou et al. 2010; Wilson and Woods 2016). Trichogramma spp. have many different hosts. Therefore, their learning ability corresponds to the generalist theory, which declares that generalist parasitoids, compared to specialists coevolved with a specific host, rely more strongly on learning plant cues to adjust their foraging behavior (Vet and Dicke 1992; Steidle and Van Loon 2003). Overall, the low innate response to tomato plants and the learning ability match the environmental unpredictability hypothesis, suggesting that it is best to learn odor cues unique to a specific time and place (Dukas 2008) rather than evolve innate responses (Papaj and Prokopy 1989). In contrast to T. achaeae and T. evanescens, the behavior of $T$. dendrolimi was not affected by associative learning. For associative learning, the small E. kuehniella eggs might have been considered a low-quality host for the relatively large $T$. dendrolimi. Indeed, female Trichogramma spp. discriminate between high- and low-quality hosts. They often visit and oviposit in fresh eggs of high-quality and use the old ones of low-quality for feeding (Kishani Farahani et al. 2015). We assume all eggs used in our experiments were adequately fresh. In our study, the associative learning experience in T. achaeae females was weaker after $24 \mathrm{~h}$ than after 6-12 h. Memory is sensitive to differences in conditioning, such as the number and type of conditioning trials, and more subtle differences, such as reward value (Kruidhof et al. 2012). Thus, only one conditioning trial is likely not enough to produce a long-lasting memory. Numerous and spaced training often leads to longer forms of memory in parasitic wasps, but there are also exceptions where a single training resulted in memory lasting for five and more days (Collatz et al. 2006).

Many parasitoids of herbivorous insects rely on odors emitted by plants (volatile organic compounds-VOCs) to find hosts (McCormick et al. 2014). Firstly, plants are in general large and produce more volatiles compared with host insects. Secondly, plants may produce volatiles in response to herbivory and egg deposition to alert natural enemies (Heil 2008). Interestingly in our study, female T. achaeae showed no difference in arrestment response between $T$. absoluta egg-infested and uninfested tomato leaves. This finding corresponds to a recent study by Gontijo et al. (2019). The same result was also found for other natural enemies of T. absoluta, such as the mirid predator Nesidiocoris tenuis (Reuter) (Hemiptera: Miridae) (Naselli et al. 2017). However, there is evidence that egg deposition from T. absoluta on tomato induces volatiles (Faria et al. 2008; Gontijo et al. 2019). Likely, the low amount of volatiles produced by a single $T$. absoluta egg-infested leaflet or the fact that the leaflet used in our experiment had been cut off from the plant may have impaired the ability of $T$. achaeae females to distinguish between infested and uninfested leaves. Laboratory studies have shown that a higher density of $T$. absoluta infestation results in releasing larger amounts of VOCs (Silva et al. 2017), which arrested more Trichogramma spp. parasitoids (Alsaedi et al. 2016). 
To disentangle the different stimuli learned within the host-plant complex was not the particular aim of our study. During emergence learning, females may have learned the tomato plant's cues from remainders of the host, induced volatiles from egg deposition, or everything simultaneously. Also, to conduct associative learning, we used factitious eggs and not eggs from T. absoluta. Therefore, we might have obtained a better result in our efficacy test if eggs of T. absoluta were used for the conditioning. However, we think this is unlikely and that, in general, Trichogramma spp. are more prone to learn stimuli of the plant than the host egg. For instance, Kaiser et al. (1989) showed that T. brassicae (as Trichogramma maidis Pintureau and Voegelé) can learn the odor of maize extract through associative learning but cannot learn the odor of host eggs or the sex pheromone of the maize pest, Ostrinia nubilalis Hübner (Lepidoptera: Crambidae). Since eggs produce no long-range cues and parasitoids rely primarily on the host plant cues for longrange detectability (reviewed by Colazza et al. 2009), we speculate that the tomato plant's odor is the strongest or only stimuli in this learning process.

While primarily laboratory-based evidence shows that parasitoids can learn cues of the plant-host complex, few attempts have been made to link it to efficacy (Kruidhof et al. 2019). Our result demonstrates that for T. achaeae, associative learning increases efficacy at the leaf and plant level under small-scale, confined conditions. Conditioning the parasitoids before their release in a biological control program might thus improve their efficiency against $T$. absoluta in the field. However, even under the confined conditions, $T$. achaeae did not achieve more than 50\% parasitism of host eggs within a four days period. Whether this results from a lack of short range host detection cues as discussed above or points to a limited efficacy of T. achaeae in the tomato system in general remains to be determined. A comparable link between conditioning and efficacy was reported by Papaj and Vet (1990) where Leptopilina heterotoma (Thomson) (Hymenoptera: Figitidae) experiencing the host habitat odor in the presence of Drosophila spp. host larvae had a 3-4 times higher chance of finding a host habitat than inexperienced females. Furthermore, T. achaeae females responded to diethyl ether extracts of tomato leaves, but not to hexane extracts, indicating that the plant odor cues involved have a low molecular weight and are water-soluble compounds (Schultz et al. 1977). Therefore, future studies should prefer diethyl ether as solvent to extract the tomato plant odor cues. The plant extracts might ultimately be used to prime parasitoids before their release in a biological control program to increase their efficacy.

In contrast to T. achaeae, associative learning did not increase the parasitism rate of $T$. evanescens in our tube experiment, nor did emergence learning for $T$. dendrolimi. Possibly, these two species have a lower capacity to cope with the tomato trichomes than $T$. achaeae or are more prone to reject $T$. absoluta eggs as host. Trichogramma spp. are known to be less effective on plants bearing trichomes (Romeis et al. 2005); therefore, females may have been arrested by the tomato leaf in the olfactometer but may have avoided foraging on tomato leaves or being hampered in their movement when released into tubes. Furthermore, Roriz et al. (2006) showed that Trichogramma spp. prefer larger eggs as hosts. Eggs of T. absoluta are much smaller than the E. kuehniella eggs used in the rearing. Thus, T. evanescens and T. dendrolimi may have avoided T. absoluta eggs for the simple reason that they were too small.

Currently, T. achaeae is mass-reared and commercially available for use against $T$. absoluta in Europe. However, the low suitability of the tomato - T. absoluta system for supporting Trichogramma spp. parasitoids results in high costs limiting their use (Cabello et al. 2009; Chailleux et al. 2012, 2013). Furthermore, the effectiveness of parasitoids to locate their host might be constrained by an initially weak response to foraging cues emanating from the crop environment and an innate tendency for dispersal upon release (Kruidhof et al. 2019). Our findings confirm the tomato plant system's low suitability for commercial Trichogramma spp. releases in its current form. Since our efficacy tests with associative learning show promising results, we can conclude that learning is a possible means of improving this suitability and will likely help retain the parasitoid T. achaeae in the field after release. However, we showed that learning is species-dependent and must therefore be adapted for each parasitoid species. Moreover, we showed that $T$. achaeae and T. evanescens do not learn the host-plant complex's odor at emergence, which is considered an attractive characteristic for mass rearing since it does not condition them on factitious hosts (Bjorksten and Hoffmann 1995).

Trichogramma spp. have been used effectively in various parts of the world through inundative releases. China has achieved successful wide-scale use thanks to its Trichogramma spp. manufacturing. The country has industrialized mass-rearing systems for cost-effective Trichogramma spp. production, which depends on mechanized processes, complex expertise to manipulate diapause, optimal use of factitious hosts, genetic methods, and novel application approaches. In the country's biggest maize production region, 35\% of the area relies on Trichogramma spp. releases to control corn borers (reviewed by Zang et al. 2021). So far, up to 24 species have been identified as potential biological control agents and can target over 120 different pests in China (Wang et al. 1998). Meanwhile, at least ten species have been further developed for field applications, such as T. dendrolimi (maize, rice, cotton), Trichogramma japonicum Ashmead (rice), T. chilonis (sugarcane, rice, cotton), Trichogramma ostriniae Pang \& Chen (maize), and Trichogramma leucaniae Pang \& Chen (soybean) (Lin 1994; Wang 
et al. 1998). China is the largest tomato producer worldwide, and T. absoluta has made its apparition (Zhang et al. 2020a). The country will likely develop a Trichogramma-based control strategy against this devastating pest (Zang et al. 2021). Since the three species tested in the present study are commercially reared in China ( $\mathrm{Li} 2007$ ), our findings can be implemented to develop this strategy.

We believe that besides assessing associative learning on a larger scale, future research should look at how this associative process can be implemented for mass production and release. Since Trichogramma spp. parasitoids are shipped as pupae in parasitized eggs, conditioning of adults can only occur at the release site providing access to factitious hosts, i.e., sterile eggs or alternative hosts that are not harmful to the crop. Plant extracts can be a successful way of mimicking the crop odor if this is missing or not strong enough to elicit an associative response. For example, the producer could provide the farmers with the parasitoid pupae and a conditioning package that contains an alternative reward and plant extract (reviewed by Kruidhof et al. 2019).

In conclusion, our study provides strong support for the learning ability of Trichogramma spp., thereby contributing to our understanding of learning processes for the improvement of biological control programs. A substantial increase in the arrestment response to the odor of tomato plants can be achieved through conditioning; however, the learning process differs between Trichogramma species. Overall, associative learning is very likely to increase the efficiency of $T$. achaeae against $T$. absoluta. Our observations nevertheless create demand for field studies on the efficiency of such conditioning at a larger scale.

\section{Authors' contributions}

JG, JR and JC designed the research. JG led the trials. YZ and GZ provided insight information regarding the pest and the parasitoids in China. JG, JR and JC analyzed the data. JG, JR and JC wrote the manuscript. All authors read, edited and approved the manuscript.

Supplementary Information The online version contains supplementary material available at https://doi.org/10.1007/s10340-022-01484-6.

Acknowledgements We wish to thank AMW Nützlinge for providing the Trichogramma dendrolimi strain, Andermatt Biocontrol for providing the Tuta absoluta population, and Mario Waldburger for the excellent technical support.

Funding Open access funding provided by Agroscope. This project was conducted within the collaborative project between IPP-CAAS and Agroscope "Biological Control of exotic arthropod pests" with funding by the Swiss Federal Office for Agriculture.
Data availability The complete raw data can be found at the Dryad repository. See (https://doi.org/10.6084/m9.figshare.14747949).

\section{Declarations}

Conflict of interest The authors declare that they have no conflict of interest.

Open Access This article is licensed under a Creative Commons Attribution 4.0 International License, which permits use, sharing, adaptation, distribution and reproduction in any medium or format, as long as you give appropriate credit to the original author(s) and the source, provide a link to the Creative Commons licence, and indicate if changes were made. The images or other third party material in this article are included in the article's Creative Commons licence, unless indicated otherwise in a credit line to the material. If material is not included in the article's Creative Commons licence and your intended use is not permitted by statutory regulation or exceeds the permitted use, you will need to obtain permission directly from the copyright holder. To view a copy of this licence, visit http://creativecommons.org/licenses/by/4.0/.

\section{References}

Alsaedi G, Ashouri A, Talaei-Hassanloui R (2016) Behavioral responses of the three Trichogramma species to different odor sources. J Entomol Zool Stud 4:19-24

Amire Y, Adili S, Fu K, Ding X, He J, Tuershun A, Guo W, Li X (2020) Control effects of 9 pesticides on tomato leafminer, Tuta absoluta (Meyrick). Xinjiang Agric Sci 12:2291-2298 (in Chinese, abstract in English)

Biondi A, Guedes RNC, Wan F-H, Desneux N (2018) Ecology, worldwide spread, and management of the invasive South American tomato pinworm, Tuta absoluta: past, present, and future. Annu Rev Entomol 63:239-258. https://doi.org/10.1146/annur ev-ento-031616-034933

Bjorksten TA, Hoffmann AA (1995) Effects of pre-adult and adult experience on host acceptance in choice and non-choice tests in two strains of Trichogramma. Entomol Exp Appl 76:49-58. https://doi.org/10.1111/j.1570-7458.1995.tb01945.x

Bjorksten TA, Hoffmann AA (1998) Plant cues influence searching behaviour and parasitism in the egg parasitoid Trichogramma $\mathrm{nr}$. brassicae. Ecol Entomol 23:355-362. https://doi.org/10.1046/j. 1365-2311.1998.00148.x

Cabello T, Gallego JR, Vila E, Soler A, del Pino M, Carnero A, Hernandez-Suarez E, Polaszek A (2009) Biological control of the South American tomato pinworm, Tuta absoluta (Lep.: Gelechiidae), with releases of Trichogramma achaeae (Hym.: Trichogrammatidae) in tomato greenhouses of Spain. IOBC/WPRS Bull 49:225-230

CABI (2021) Invasive Species Compendium. CAB International, Wallingford

Cascone P, Carpenito S, Slotsbo S, Iodice L, Sørensen JG, Holmstrup M, Guerrieri E (2015) Improving the efficiency of Trichogramma achaeae to control Tuta absoluta. Biocontrol 60:761-771. https:// doi.org/10.1007/s10526-015-9684-1

Chailleux A, Desneux N, Seguret J, Do Thi Khanh H, Maignet P, Tabone E (2012) Assessing European egg parasitoids as a mean of controlling the invasive South American tomato pinworm Tuta absoluta. PLoS ONE 7:e48068. https://doi.org/10.1371/journal. pone. 0048068

Chailleux A, Biondi A, Han P, Tabone E, Desneux N (2013) Suitability of the pest-plant system Tuta absoluta (Lepidoptera: 
Gelechiidae)-tomato for Trichogramma (Hymenoptera: Trichogrammatidae) parasitoids and insights for biological control. J Econ Entomol 106:2310-2321. https://doi.org/10.1603/ec13092

Clavijo Mccormick A, Gershenzon J, Unsicker SB (2014) Little peaks with big effects: establishing the role of minor plant volatiles in plant-insect interactions. Plant Cell Environ 37:18361844. https://doi.org/10.1111/pce. 12357

Colazza S, Peri E, Salerno G, Conti E (2009) Host searching by egg parasitoids: exploitation of host chemical cues. In: Cônsoli FL, Parra JRP, Zucchi RA (eds) Progress in biological control. Springer, Netherlands, pp 57-147

Collatz J, Müller C, Steidle JLM (2006) Protein synthesis-dependent long-term memory induced by one single associative training trial in the parasitic wasp Lariophagus distinguendus. Learn Mem 13:263-266. https://doi.org/10.1101/lm.192506

Desneux N, Han P, Mansour R et al (2021) Integrated pest management of Tuta absoluta: practical implementations across different world regions. J Pest Sci. https://doi.org/10.1007/ s10340-021-01442-8

Dukas R (2008) Evolutionary biology of insect learning. Annu Rev Entomol 53:145-160. https://doi.org/10.1146/annurev.ento.53. 103106.093343

Dukas R, Duan JJ (2000) Potential fitness consequences of associative learning in a parasitoid wasp. Behav Ecol 11:536-543. https://doi.org/10.1093/beheco/11.5.536

El-Wakeil NE (2007) Evaluation of efficiency of Trichogramma evanescens reared on different factitious hosts to control Helicoverpa armigera. J Pest Sci 80:29-34. https://doi.org/10.1007/ s10340-006-0150-9

Faria CA, Torres JB, Fernandes AMV, Farias AMI (2008) Parasitism of Tuta absoluta in tomato plants by Trichogramma pretiosum Riley in response to host density and plant structures. Ciência Rural 38:1504-1509. https://doi.org/10.1007/ s40267-016-0369-3

Gandolfi M, Mattiacci L, Dorn S (2003) Preimaginal learning determines adult response to chemical stimuli in a parasitic wasp. Proc R Soc Lond B Sci 270:2623-2629. https://doi.org/10.1098/rspb. 2003.2541

Giorgini M, Guerrieri E, Cascone P, Gontijo L (2019) Current strategies and future outlook for managing the neotropical tomato pest Tuta absoluta (Meyrick) in the mediterranean basin. Neotrop Entomol 48:1-17. https://doi.org/10.1007/s13744-018-0636-1

Giunti G, Canale A, Messing RH, Donati E, Stefanini C, Michaud JP, Benelli G (2015) Parasitoid learning: Current knowledge and implications for biological control. Biol Control 90:208-219. https://doi.org/10.1016/j.biocontrol.2015.06.007

Gontijo L, Cascone P, Giorgini M, Michelozzi M, Rodrigues HS, Spiezia G, Lodice L, Guerrieri E (2019) Relative importance of host and plant semiochemicals in the foraging behavior of Trichogramma achaeae, an egg parasitoid of Tuta absoluta. J Pest Sci 92:1479-1488. https://doi.org/10.1007/s10340-019-01091-y

Gu H, Dorn S (2000) Genetic variation in behavioral response to herbivore-infested plants in the parasitic wasp, Cotesia glomerata (L.) (Hymenoptera: Braconidae). J Insect Behav 13:141-156. https:// doi.org/10.1023/A:1007723811573

Guedes RNC, Roditakis E, Campos MR, Haddi K, Bielza P, Siqueira HAA, Tsagkarakou A, Vontas J, Nauen R (2019) Insecticide resistance in the tomato pinworm Tuta absoluta: patterns, spread, mechanisms, management and outlook. J Pest Sci 92:1329-1342. https://doi.org/10.1007/s10340-019-01086-9

Han P, Zhang Y-N, Lu Z-Z, Wang S, Ma D-Y, Biondi A, Desneux N (2018) Are we ready for the invasion of Tuta absoluta? unanswered key questions for elaborating an integrated Pest management package in Xinjiang, China. Entomol Gen 38:113-125. https://doi.org/10.1127/entomologia/2018/0739
Hare JD, Morgan DJW, Nguyun T (1997) Increased parasitization of California red scale in the field after exposing its parasitoid, Aphytis melinus, to a synthetic kairomone. Entomol Exp Appl 82:73-81. https://doi.org/10.1046/j.1570-7458.1997.00115.x

Hastings A, Godfray HCJ (1999) Learning, host fidelity, and the stability of host-parasitoid communities. Am Nat 153:295-301. https://doi.org/10.1086/303172

Heil M (2008) Indirect defence via tritrophic interactions. New Phytol 178:41-61. https://doi.org/10.1111/j.1469-8137.2007. 02330.x

Hoffmann MP, Ode PR, Walker DL, Gardner J, Van Nouhuys S, Shelton AM (2001) Performance of Trichogramma ostriniae (Hymenoptera: Trichogrammatidae) reared on factitious hosts, including the target host, Ostrinia nubilalis (Lepidoptera: Crambidae). Biol Control 21:1-10. https://doi.org/10.1006/bcon.2000.0912

Kaiser L, Pham-Delegue MH, Masson C (1989) Behavioural study of plasticity in host preferences of Trichogramma maidis (Hym.: Trichogrammatidae). Physiol Entomol 14:53-60. https://doi.org/ 10.1111/j.1365-3032.1989.tb00936.x

Kester KM, Barbosa P (1991) Postemergence learning in the insect parasitoid, Cotesia congregata (Say) (Hymenoptera: Braconidae). J Insect Behav 4:727-742. https://doi.org/10.1007/BF01052227

Kishani Farahani H, Ashouri A, Goldansaz SH, Farrokhi S, Ainouche A, van Baare J (2015) Does Wolbachia infection affect decisionmaking in a parasitic wasp? Entomol Exp Appl 155:102-116. https://doi.org/10.1111/eea.12293

Kruidhof HM, Pashalidou FG, Fatouros NE, Figueroa IA, Vet LEM, Smid HM, Huigens ME (2012) Reward value determines memory consolidation in parasitic wasps. PLoS ONE 7(8):e39615. https:// doi.org/10.1371/journal.pone.0039615

Kruidhof HM, Kostenko O, Smid HM, Vet LEM (2019) Integrating parasitoid olfactory conditioning in augmentative biological control: potential impact, possibilities, and challenges. Front Ecol Evol 7:84. https://doi.org/10.3389/fevo.2019.00084

Li Z-X (2007) Molecular differentiation of the four most commonly occurring Trichogramma (Hymenoptera: Trichogrammatidae) species in China. Eur J Entomol 104:363-367. https://doi.org/10. 14411/eje.2007.054

Lin NQ (1994) Systematic studies of Chinese Trichogrammmatidae. Special Publication No 4 Chongqing Publishing House, Chongqing, China, Contributions of the Biological Control Research Institute, Fujian Agricultural University (in Chinese with English abstract)

Mansour R, Brévault T, Chailleux A, Cherif A, Grissa-Lebdi K, Haddi K, Mohamed SA, Nofemela RS, Oke A, Sylla S et al (2018) Occurrence, biology, natural enemies and management of Tuta absoluta in Africa. Entomol Gen 38:83-112. https://doi.org/10. 1127/entomologia/2018/0749

Meiners T, Hacker NK, Anderson P, Hilker M (2005) Response of the elm leaf beetle to host plants induced by oviposition and feeding: the infestation rate matters. Entomol Exp Appl 115:171-177. https://doi.org/10.1111/j.1570-7458.2005.00280.x

Milonas PG, Anastasaki E, Partsinevelos G (2019) Oviposition-induced volatiles affect electrophysiological and behavioral responses of egg parasitoids. Insects 10:437. https://doi.org/10.3390/insects101 20437

Naselli M, Zappalà L, Gugliuzzo A, Garzia GT, Biondi A, Rapisarda C, Cincotta F, Condurso C, Verzera A, Siscaro G (2017) Olfactory response of the zoophytophagous mirid Nesidiocoris tenuis to tomato and alternative host plants. Arthropod Plant Interact 11:121-131. https://doi.org/10.1007/s11829-016-9481-5

NCSS 2020 Statistical software (2020). NCSS, LLC. Kaysville, Utah, USA, ncss.com/software/ncss.

Nikbin R, Sahragard A, Hosseini M (2014) Age-specific functional response of Trichogramma brassicae (Hymenoptera: Trichogrammatidae) parasitizing different egg densities of Ephestia kuehniella 
(Lepidoptera: Pyralidae). J Agric Sci Technol 16(6):1217-1227. https://doi.org/10.1006/bcon.1993.1007

Nordlund DA, Chalfant RB, Lewis WJ (1985) Response of Trichogramma pretiosum females to extracts of two plants attacked by Heliothis zea. Agric Ecosyst Environ 12:127-133. https://doi.org/ 10.1016/0167-8809(85)90073-8

Papaj DR, Prokopy RJ (1989) Ecological and evolutionary aspects of learning in phytophagous insects. Annu Rev Entomol 34:315-350. https://doi.org/10.1146/annurev.en.34.010189.001531

Papaj DR, Vet LEM (1990) Odor learning and foraging success in the parasitoid, Leptopilina heterotoma. J Chem Ecol 16:3137-3150. https://doi.org/10.1007/BF00979616

Pashalidou FG, Huigens ME, Dicke M, Fatouros NE (2010) The use of oviposition-induced plant cues by Trichogramma egg parasitoids. Ecol Entomol 35:748-753. https://doi.org/10.1111/j.1365-2311. 2010.01235.x

Prevost G, Lewis WJ (1990) Heritable differences in the response of the braconid wasp Microplitis croceipes to volatile allelochemicals. J Insect Behav 3:277-287. https://doi.org/10.1007/BF01052110

Romeis J, Babendreier D, Wäckers FL, Shanower TG (2005) Habitat and plant specificity of Trichogramma egg parasitoids - underlying mechanisms and implications. Basic Appl Ecol 6:215-236. https://doi.org/10.1016/j.baae.2004.10.004

Romeis J, Shanower TG, Zebitz CPW (1997) Volatile plant infochemicals mediate plant preference of Trichogramma chilonis. J Chem Ecol 23:2455-2465. https://doi.org/10.1023/B:JOEC.00000 06659.06960.ed

Roriz V, Oliveira L, Garcia P (2006) Host suitability and preference studies of Trichogramma cordubensis (Hymenoptera: Trichogrammatidae). Biol Control 36:331-336. https://doi.org/10.1016/j. biocontrol.2005.09.002

Schultz TH, Flath RA, Mon TR, Eggling SB, Teranishi R (1977) Isolation of volatile components from a model system. J Agric Food Chem 25:446-449. https://doi.org/10.1021/jf60211a038

Silva DB, Weldegergis BT, Van Loon JJA, Bueno VHP (2017) Qualitative and quantitative differences in herbivore-induced plant volatile blends from tomato plants infested by either Tuta absoluta or Bemisia tabaci. J Chem Ecol 43:53-65. https://doi.org/10.1007/ s10886-016-0807-7

Takasu K, Lewis WJ (2003) Learning of host searching cues by the larval parasitoid Microplitis croceipes. Entomol Exp Appl 108:7786. https://doi.org/10.1046/j.1570-7458.2003.00070.x

Thomson MS, Stinner RE (1990) The scale response of Trichogramma (Hymenoptera: Trichogrammatidae): variation among species in host specificity and the effect of conditioning. Entomophaga 35:7-21. https://doi.org/10.1007/BF02374296

Tropea Garzia G, Siscaro G, Biondi A, Zappalà L (2012) Tuta absoluta, a South American pest of tomato now in the EPPO region: biology, distribution and damage. EPPO Bull 42(2):205-210. https:// doi.org/10.1111/epp.2556

Urbaneja A, González-Cabrera J, Arnó J, Gabarra R (2012) Prospects for the biological control of Tuta absoluta in tomatoes of the Mediterranean basin. Pest Manag Sci 68:1215-1222. https://doi. org/10.1002/ps.3344

van Lenteren JC (2000) Success in biological control of arthropods by augmentation of natural enemies. In: Gurr G, Wratten S (eds) Biological control: measures of success. Springer, Amsterdam, pp 77-103
Vet LEM, Dicke M (1992) Ecology of infochemical use by natural enemies in a tritrophic context. Annu Rev Entomol 37:141-172. https://doi.org/10.1146/annurev.en.37.010192.001041

Vet LEM, Groenewold AW (1990) Semiochemicals and learning in parasitoids. J Chem Ecol 16:3119-3135. https://doi.org/10.1007/ BF00979615

Waage JK, Ming NS (1984) The reproductive strategy of a parasitic wasp: I. optimal progeny and sex allocation in Trichogramma evanescens. J Anim Ecol 53:401-415. https://doi.org/10.2307/4525

Wang CL, Zhang J, Huo ST (1998) Study, reproduction and utilization of Trichogramma. In: Bao JZ, Gu DX (eds) Biological Control in China. Shanxi Science and Technology Press, Taiyuan, pp 67-123 (in Chinese)

Wilson JK, Woods HA (2016) Innate and learned olfactory responses in a wild population of the egg parasitoid Trichogramma (Hymenoptera: Trichogrammatidae). J Insect Sci 16:1-8. https://doi.org/ 10.1093/jisesa/iew108

Zang LS, Wang S, Zhang F, Desneux N (2021) Biological control with Trichogramma in China: history, present status, and perspectives. Annu Rev Entomol 66:463-484. https://doi.org/10.1146/annur ev-ento-060120-091620

Zappalà L, Biondi A, Alma A, Al-Jboory IJ, Arnò J, Bayram A, Chailleux A, El-Arnaouty A, Gerling D, Guenaoui Y et al. (2013) Natural enemies of the South American moth, Tuta absoluta, in Europe, North Africa and Middle East, and their potential use in pest control strategies. J Pest Sci 86:635-647. https://doi.org/10. 1007/s10340-013-0531-9

Zhang G-F, Ma D-Y, Wang Y-S, Gao Y-H, Liu W-X, Zhang R, FU W-J, Xian X-Q, Wang J, Kuang M, Wan FH, (2020a) First report of the South American tomato leafminer, Tuta absoluta (Meyrick), in China. J Integr Agric 19:1912-1917. https://doi.org/10.1016/ S2095-3119(20)63165-3

Zhang G-F, Xian X-Q, Zhang Y-B, Zhang R, Ma D-Y, Liu W-X, Gao Y-H, Wang J, Yang Z-L, Li Q-H, Wang Y-S, Xue Y-T, Wan F-H (2020b) Warning of the dispersal of a newly invaded alien species, the tomato leaf miner Tuta absoluta (Meyrick), in China. Plant Protection 46:281-286. https://doi.org/10.16688/j.zwbh.20190 61 (in Chinese)

Zhang G-F, Zhang Y-B, Zhang J, Liu W-X, Wang Y-S, Wan F-H, Su C-L, Liu H, Wang F-L, Zhao L, Li Q-H, Wang S-M, Jiang J-Q (2020c) Laboratory toxicity and field control efficacy of biopesticide Bacillus thuringiensis G033A on the South American tomato leafminer Tuta absoluta (Meyrick), a new invasive alien species in China. Chinese Journal of Biological Control 36:175-183 (in Chinese)

Zhang G-F, Xian X-Q, Zhang Y-B, Liu W-X, Liu H, Feng X-D, Wang Y-S, Gao Y-H, Zhang R, Li Q-H, Wan F-H, Fu W-J, Wang J, Kuang M, Yang W-J, Rao X, Gao Y, Dai A-M (2021) Outbreak of the South American tomato leafminer Tuta absoluta in the Chinese mainland: geographic expansion and host plant increase. Pest Manag Sci 77(12):5475-5488. https://doi.org/10.1002/ps.6588

Publisher's Note Springer Nature remains neutral with regard to jurisdictional claims in published maps and institutional affiliations. 